\title{
Professional Development Needs in a Virtual Teaching and Learning Environment
}

\author{
Dahee Chung ${ }^{1}$ and Sang E Park ${ }^{2 *}$ \\ ${ }^{1}$ DMD candidate, Class of 2024, Harvard School of Dental Medicine, Massachusetts, USA \\ ${ }^{2}$ Associate Dean for Dental Education, Harvard School of Dental Medicine, Massachusetts, USA
}

Submission: July 02, 2021; Published: July 14, 2021

"Corresponding author: Sang E Park, Associate Dean for Dental Education, Harvard School of Dental Medicine, Massachusetts, USA

Abstract

Introduction: The purpose of the study was to evaluate the faculty perspectives in a virtual teaching and learning environment during the COVID-19 pandemic.

Methods: This was a survey-based study of ladder faculty members at Harvard School of Dental Medicine (HSDM) investigating information on the challenges and adaptations in teaching methods that were made related to the COVID-19 pandemic. It also questioned the preferred types, length, times and content of faculty development programs.

Results: The results showed that a majority $(n=31,75.6 \%$ ) of the 56 total participants felt the move to remote learning have Some Impact or Major Impact on the effectiveness of their teaching. Some of the major concerns that faculty expressed were 'Engagement with students' ( $\mathrm{n}=$ $30,41.67 \%$ ) and 'Use of technology' ( $n=16,22.2 \%$ ). Also, 'Designing for online learning,' 'Classroom technology' and 'Poll Everywhere' were the topics that many faculty members responded found Very Interested. The majority $(n=44,62.8 \%$ ) of respondents preferred the online format rather than the in-person format in terms of faculty development program offerings.

Conclusion: In order to adapt into the new virtual learning environment, robust faculty development programs should support the continuous designing of pedagogical approaches for a dynamic dental curriculum that will continue to challenge the students and engage the faculty.

Keyword: Faculty development; Predoctoral education; COVID-19 pandemic; Curriculum development

\section{Introduction}

Faculty development is critical for teaching and learning in dental education, as it provides opportunities for faculty to be exposed to knowledge and skills that could prepare them to teach and assess the changing needs of students [1]. However, robust programming in dental schools may have been lacking due to various limiting factors related to lack of resources, such as financial support and time for faculty [2]. The important role of faculty development in general has been widely recognized and is not limited to dental education [3,4]. A number of studies of medical school faculty development programs found that they were effective at developing teaching skills, building colleague relationships, initiating curriculum changes, and contributing to overall academic advancements [5,6]. The COVID-19 pandemic has pushed the education system to abruptly change into a virtual teaching and learning format. Thus, dental faculty have had to adapt their educational content into an online format requiring significant additional efforts surrounding teaching methodologies and according to assessment needs. The virtual learning environment prompted by the COVID-19 pandemic has further propelled the need for institutions not only to sustain dental education programs, but also to develop educational approaches and methodologies that could accommodate the demands of students and engage the faculty in the new education era.

Faculty support and training during the rapidly changing virtual teaching and learning environment is essential. However, few studies have been available to shed light on faculty perspectives on remote teaching, and additional research is necessary to explore the needs of faculty in the virtual teaching environment. Understanding the unique nature and specific needs for providing faculty development experience in learning and teaching could shed valuable information to both faculty and students. The purpose of this study was to evaluate the perspectives of faculty on faculty training and development during the COVID-19 pandemic through identifying the need and the type of support for them.

\section{Methods}

The study protocol was approved by the Harvard Medical School and Harvard School of Dental Medicine Institutional Review Board (number: IRB20-2056). The survey-based study included the ladder faculty members at Harvard School of Dental 
Medicine (HSDM) during the COVID-19 pandemic. The survey was distributed in late June of 2020 to ladder faculty members by email about their interest in faculty development opportunities. Two separate reminders were sent approximately one week apart in July 2020. The survey contained 19 questions with a combination of multiple-choice and free response questions. The survey questioned the preferred types, length, times and content of faculty development programs, in addition to the challenges and adaptations in teaching that were made due to the COVID-19 pandemic. Using the Likert scale, the survey asked participants about their interest level in attending programs containing topics such as experiential learning, feedback in clinical settings, assessment and rubric designs, diversity and inclusion in the classroom, and peer learning. Furthermore, the survey explored their interest level in attending programming on academic technology topics such as Zoom (Zoom Video Communications, Inc. San Jose, CA) online meetings, online learning designs, intellectual property, classroom technology, Poll Everywhere (Poll Everywhere, San Francisco, CA), presentation software, universal design, and Canvas (Canvas Instructure Inc., Salt Lake City, UT) technology. The survey was administered on the platform of Qualtrics (Qualtrics International Inc. Washington, D.C.) and descriptive statistical analysis was performed to analyze the results of data.

\section{Results}

Fifty-six faculty members responded to the survey of the 125 ladder faculty members at Harvard School of Dental Medicine (HSDM) resulting in a response rate of $44.8 \%$. The majority of respondents $(71.4 \%, n=40)$ expressed a general need for faculty development programs. In terms of change into a virtual learning environment due to the COVID-19 pandemic, a majority of these faculty members (75.6\%) stated that the move to remote learning had Major Impact or Some Impact on the effectiveness of their teaching. Some of the major concerns they expressed were engagement with students $(41.67 \%)$ and use of technology (22.2\%). Few also expressed concerns with access to teaching resources $(13.89 \%)$, use of technology $(22.2 \%)$ and unreliable internet access (9.72\%) (Figure 1). Twelve participants submitted narrative comments that Zoom video communication, especially the breakout and poll features, has been the most useful in remote teaching and learning. Some of the tools and techniques the respondents would like to learn more about were the Canvas learning management system, effective ways of engaging with students, and asynchronous learning.

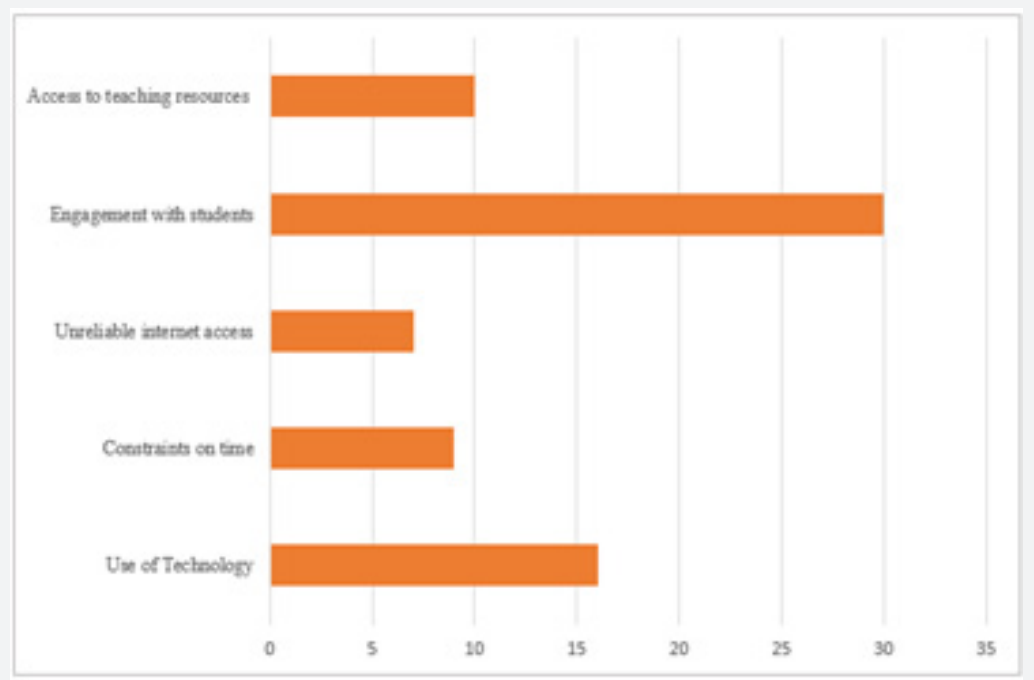

Figure 1: Faculty perceived challenges with remote teaching

Further analysis of the survey results revealed that the respondents were interested in having guest speakers and presentations $(21.1 \%)$, mentoring $(20.3 \%)$, webinars $(21.1 \%)$, and workshops (20.3\%) rather than book discussion (4\%) (Figure 2). The majority $(62.8 \%, n=44)$ of respondents preferred the online format rather than the in-person format. Of that group of 44 respondents, $63.6 \%$ preferred the online synchronous live format while $36.4 \%$ participants preferred the self-paced recorded format. About half of the respondents (48.28\%) reported that they preferred one hour for the length of faculty development program and $26.6 \%$ of respondents reported they preferred less than three hours. Respondents most often indicated that they do not have a preference of the specific time they would like to participate in the program (37.7\%), and lunchtime from noon to $1 \mathrm{pm}$ was the most popular among the options (32.08\%) (Table 1).

The respondents were asked to rate their interest level in attending programming in different teaching and learning topics (Figure 3). The types of programming that respondents considered most essential were "Designing authentic assessments" and "Race, 
Gender, Sexual Orientation, and Religious Issues in the classroom” with $18 \%$ and $20 \%$ of total respondents choosing the option "consider it essential" respectively. The most popular options that a majority of respondents expressed interest in were "Feedback and assessment in clinical settings" and "Peer learning" where $35 \%$ and $32.5 \%$ of respondents reported Very Interested. Some respondents also chose the interest option for "Experiential learning". The respondents were also asked to rate their interest in attending programming in academic technology topics (Figure 4). "Designing for online learning", "Classroom technology” and
"Poll Everywhere" were the topics that many responded as Very Interested with $29 \%, 30 \%$, and $25 \%$ response rate. Respondents were often also interested in learning more about different Canvas learning management system topics such as "online quizzes and exams", "grading and assignments", "communicating with students" and "creating and posting content" with $32 \%$ response rate. They also included narrative comments that they would like to see the program focused on "online teaching technology", "rubrics to self-assess how effective we are at teaching" or "inclusive teaching practices".

Figure 2: Faculty preference on the types of development opportunities.

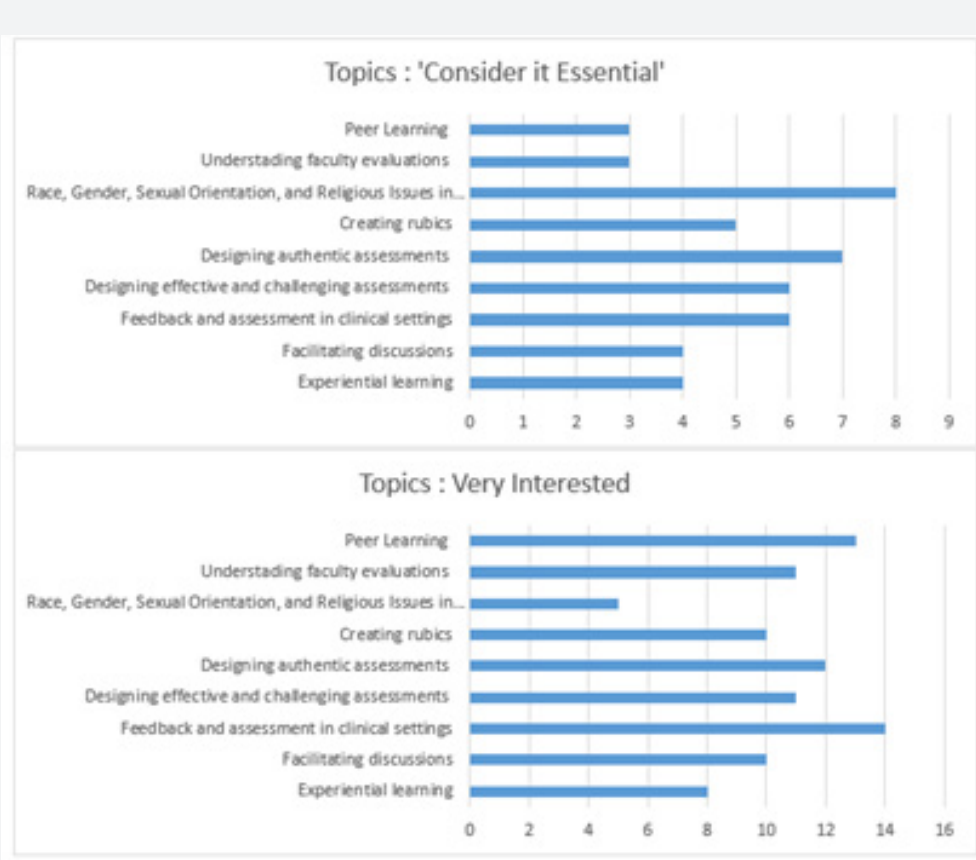

Figure 3: Faculty interests in attending programing on the Teaching and Learning topics. 


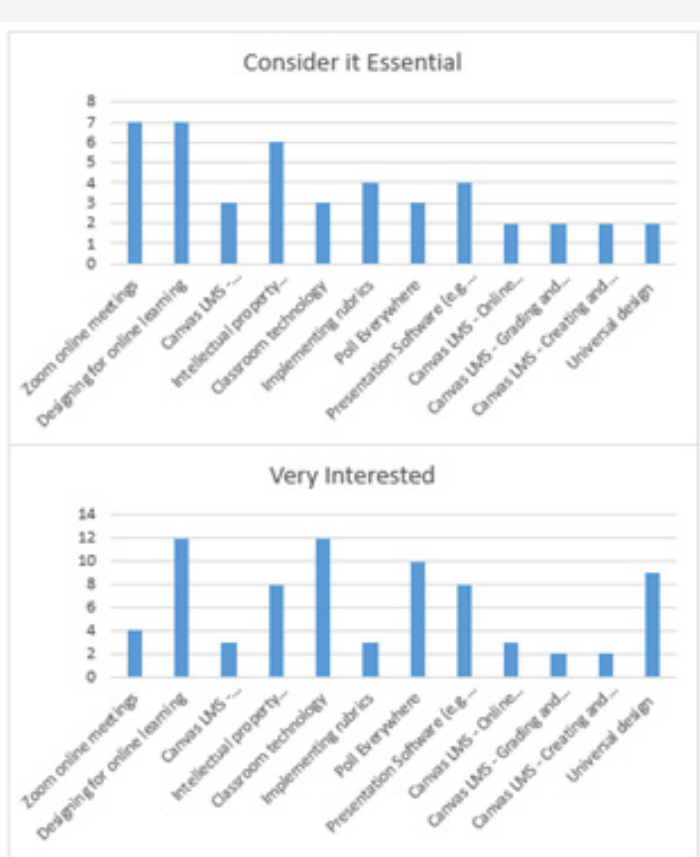

Figure 4: Interests in attending programming on academic technology topics.

Table 1: Preferences in Faculty Development Programs.

\begin{tabular}{|c|c|}
\hline Questions & Respondents \\
\hline Preferred Format & N $=70$ \\
\hline In Person & $47.14 \%(26)$ \\
\hline Online, synchronous (live) & $22.86 \%(16)$ \\
\hline Online, asynchronous (recording/self-paced) & $\mathrm{N}=58$ \\
\hline Preferred Length & $48.28 \%(28)$ \\
\hline One hour & $27.59 \%(16)$ \\
\hline Less than three hours & $5.17 \%(3)$ \\
\hline Half Day & $6.90 \%(4)$ \\
\hline Full Day & $12.07 \%(7)$ \\
\hline No preference & $\mathrm{N}=53$ \\
\hline Preferred Times & $16.98 \%(9)$ \\
\hline Morning (9AM - Noon) & $32.08 \%(17)$ \\
\hline Lunchtime (Noon - 1PM) & $13.21 \%(7)$ \\
\hline Afternoon (1PM - 4PM) & $37.74 \%(20)$ \\
\hline No preference & \\
\hline
\end{tabular}

\section{Discussion}

Dental schools are encountering a shortage of full-time faculty members and are exposed to the additional challenges related to the COVID-19 pandemic requiring an abrupt switch to the virtual learning environment [7]. The pandemic has required dental programs to adjust and rearrange their curricula given the remote situation requiring the use of technology for teaching and learning. It was important during the COVID-19 pandemic, with a unique need for a new teaching environment, to provide robust faculty development programs that could benefit both faculty and students in their remote learning experiences. The results of the current survey found that the majority of faculty were interested in participating in faculty training programs. Furthermore, the respondents expressed interests in having programs especially focused on different pedagogical technologies such as the Canvas learning management system or Zoom video communications. 
The effective use of alternative pedagogical approaches, including the integration of emerging technologies such as online and blended learning, has been on the agenda of dental schools in the United States since before the pandemic [8,9]. However, faculty who attempt to continue teaching in the way they were taught may be confronted with the challenge of developing digital pedagogies and some may not have the skill set to implement them effectively $[10,11]$. According to available literature, the success of e-learning depends on the attitudes and interactive teaching styles of the faculty, as well as on the experience and attitudes of students with regard to technology [12]. Thus, it would be essential to guide the faculty how to familiarize with interactive teaching through online platforms using various faculty development programs [13].

According to Hung et al., students generally rated their online curriculum positively, suggesting that the current crisis might offer dental schools opportunities to leverage technology in new ways that enhance dental education. The study showed that while most students had experience with online education, many faculty members lacked both experience and expertise using technology and the various online educational platforms.14 According to Turkyilmaz et al., while students are digitally literate, using technology daily, educators have relied primarily on textbooks, handouts, and notes during lectures.15 Furthermore, students observed that faculty estimated to be under 50 years of age were more likely to incorporate e-learning into courses and more likely to use social media for communication [15].

The results of the study showed that promoting student engagement was a significant issue for remote teaching. Some studies suggest that Zoom lectures that use breakout rooms to work on questions in smaller groups helped with student engagement [16]. Interactive sessions that implement ungraded quizzes or polls during online lectures are also beneficial, so that students can focus on specific areas for improvement and stay engaged. Therefore, to facilitate the transition into virtual dental education, it is necessary to develop effective instructional methods that meet course objectives, increase interactivity, and enhance student engagement $[16,17]$

According to Tricio et al., faculty members strongly agreed that training in teaching and learning skills helped them improve the quality of their students' learning and they witnessed improvement in their teaching and learning activities, assessment tasks and intended learning outcomes [18]. Furthermore, according to Kaczmarek et al., many faculty members reported increased faculty burnout due to virtual teaching difficulties such as technological challenges, instability and associated anxiety.16 Dental faculty has been experiencing high levels of burnout, and the sudden transition to online dental education has added another stressful sources of burnout among faculty [19]. Therefore, it will be not only beneficial, but critical to have faculty development programs geared toward technology and online educational platforms in the context of change into virtual and remote learning during a pandemic era.
The study by McAndrew et al. showed that there had been an almost six-fold rise in the number of offices of faculty development at institutions since 2001 [20]. However, there have also been financial barriers for faculty development programs, since the funds for faculty training programs might be provided on a more flexible basis in most schools. According to Steinert et al., sustained financial support is instrumental in the success of faculty development efforts [21]. Thus, allocation of institutional financial resources may be critical to support and to create new faculty development programs.

In addition, there are significant time constraints for the faculty, as they have multiple responsibilities including patient care, research, education and administrative responsibilities. As the survey results showed, the faculty preferred online faculty development programs due to ease of scheduling and less time commitment. According to Cook et al., faculty members are affected by issues of time and location so clinical calendars, committee and teaching schedules, and travel commitments can all combine to make scheduling in-person faculty development activities difficult [22]. To support active participation in faculty development programs, institutions can play a role by allowing flexibility in administrative workload or faculty schedules so that they can devote time and efforts to faculty training programs. Furthermore, the institutions can create various types of faculty development programs with different durations so that faculty can commit to these programs given sufficient flexibility. Moreover, institutions can consider expanding their infrastructure to support online faculty development programs by allocating financial and human resources to support the programs.

Organizations such as the American Dental Education Association (ADEA) have extended faculty development training programs focused on needs during the COVID-19 pandemic. The ADEA programs have helped faculty and administrators to share ideas and recommendations for teaching modalities on ADEA Connect, including online education and other creative teaching methods, during this unprecedented time [23,24]. In addition, as mentioned in O'Neill and Taylor study, the creation of a Faculty Development ADEA Special Interest Group (SIG) to support collaborations and formalize the reporting of activities of faculty development personnel at dental schools would further help faculty to navigate various faculty development programs in current times [25]. Administration may explore creative means to encourage faculty to participate in these programs including protected faculty development time and opportunities. With regards to expectations and responsibilities, institutions could further consider the participations in these faculty development programs with regard to promotion and tenure decisions for faculty. The limitation of this study is that the survey was conducted only in one dental school. The faculty in other schools might have different perspectives on their faculty development programs. Furthermore, because the pandemic is evolving and the curriculum has been changing rapidly, faculty may change their opinions based on the curriculum modification [26]. 


\section{Conclusion}

The abrupt change to a virtual learning environment during the COVID-19 pandemic has significantly impacted faculty perspectives of the effectiveness of their teaching. It is essential to develop faculty training programs in teaching and learning that can support the faculty to continue providing educational needs of students through virtual learning format. Dental schools and organizations should consider allocating institutional resources to develop and utilize various faculty development programs focused on current technologies to contribute positive changes to the paradigm of dental education for faculty and students.

\section{References}

1. Hum L, Park, SE (2016) Impact on Junior Faculty of Teaching Opportunities During Predoctoral Education: A Survey-Based Study. J Dent Educ 80(4): 416-421.

2. Johnston C, Ganas J, Jeong YN, Nevius A, Bassir SH, et al. (2019) Faculty Development Initiatives in Academic Dentistry: A Systematic Review. J Dent Educ 83(9):1107-1117.

3. Bland CJ, Seaquist E, Pacala JT, Center B, Finstad D (2002) One school's strategy to assess and improve the vitality of its faculty. Acad Med 77(5): 368-376.

4. Benor DE (2002) Faculty development, teaching training, and teacher accreditation in medical education: twenty years from now. Med Teach 22(5): 503-512.

5. Sachdeva AK (2000) Faculty development and support needed to integrate the learning of prevention in the curricula of medical schools. Acad Med 75(7 Suppl): S35-S42.

6. Hewson MG, Copeland HL, Fishleder AJ (2001) What's the use of faculty development? Program evaluation using retrospective selfassessments and independent performance ratings. Teach Learn Med 13(3): 153-160.

7. Sabato E, DeCastro JE, Fenesy K (2014) An Innovative, Comprehensive Faculty Recruitment and Development Program at One U.S. Dental School: Early Results. J Dent Educ 81(6): 649-657.

8. Hendricson WD, Anderson E, Andrieu SC, (2007) Does faculty development enhance teaching effectiveness? J Dent Educ 71(12): 1513-1533.

9. Zheng M, Bender D, Nadershahi N (2017) Faculty professional development in emergent pedagogies for instructional innovation in dental education. Eur J Dent Educ 21(2): 67-78.

10. Gates P, Ubu N, Smithey L, Jennifer Rogers, Karl Haden N, et al. (2012) Faculty development for underrepresented minority dental faculty and residents. J Dent Educ 77(3): 276-291.

11. Steinert Y, Mann K, Centeno A, Diana Dolmans, John Spencer, et al (2006) A systematic review of faculty development initiatives designed to improve teaching effectiveness in medical education: BEME Guide No. 8. Med Teach 28(6): 497-526.
12. Webster J, Hackley P (1997) Teaching effectiveness in technologymediated distance learning. Acad Manage J 40: 1282-1309.

13. Møystad A, Lycke KH, Barkvoll TA, Lauvås P (2015) Faculty development for clinical teachers in dental education. Eur J Dent Educ 19: 149-155.

14. Hung M, Licari FW, Hon ES, Evelyn Lauren, Sharon Su, et al. (2021) In an era of uncertainty: Impact of COVID-19 on dental education. J Dent Educ 85(2): 148-156.

15. Turkyilmaz I, Hariri NH, Jahangiri L (2019) Student's Perception of the Impact of E-learning on Dental Education. J Contemp Dent Pract 20(5): 616-621.

16. Kaczmarek K, Chen E, Ohyama H (2020) Distance learning in the COVID-19 era: Comparison of student and faculty perceptions. J Dent Educ p. 1- 3.

17. Manogue M, McLoughlin J, Christersson C, et al. (2010) Curriculum structure, content, learning and assessment in European undergraduate dental education. Dublin, Ireland: Association for Dental Education in Europe, Task Force II p. 1-18

18. Tricio JA, Montt JE, Ormeño AP, Del Real AJ, et al. (2014) Impact of Faculty Development Workshops in Student-Centered Teaching Methodologies on Faculty Members' Teaching and Their Students' Perceptions. J Dent Edu 81(6): 675-684.

19. Kennedy EN, Krupat E, Park SE (2020) Assessing Dental Faculty Wellness and Burnout in Northeast U.S. Dental Schools. Journal of the Massachusetts Dental Society Winter 2020. Massachusetts Dental Society.

20. McAndrew M, Horvath Z, Atiyeh LE (2018) A Survey of Faculty Development in U.S. and Canadian Dental Schools: Types of Activities and Institutional Entity with Responsibility. J Dent Educ 82(11): 11271139.

21. Steinert Y, Mann K, Anderson B, Bonnie Maureen Barnett, Angel Centeno, et al. (2016) A systematic review of faculty development initiatives designed to enhance teaching effectiveness: A 10-year update. BEME guide no. 40. Med Teach 38(8):769-86.

22. Cook DA, Steinert Y (2013) Online learning for faculty development: a review of the literature. Med Teach 35(11): 930-907.

23. Iyer P, Aziz K, Ojcius DM (2020) Impact of COVID-19 on dental education in the United States. J Dent Educ 84(6): 718- 722.

24. (2017) American Dental Education Association. ADEA policy statements: recommendations and guidelines for academic dental institutions. J Dent Educ 81(7): 869-881.

25. O'Neill PN, Taylor CD (2001) Responding to the need for faculty development: a survey of U.S. and Canadian dental schools. J Dent Educ 65(8): 768-776.

26. Desai BK (2020) Clinical implications of the COVID-19 pandemic on dental education. J Dent Educ 84(5): 512 


\section{Your next submission with Juniper Publishers} will reach you the below assets

- Quality Editorial service

- Swift Peer Review

- Reprints availability

- E-prints Service

- Manuscript Podcast for convenient understanding

- Global attainment for your research

- Manuscript accessibility in different formats ( Pdf, E-pub, Full Text, Audio)

- Unceasing customer service

Track the below URL for one-step submission https://juniperpublishers.com/online-submission.php 